\title{
SOBRE LA POTESTAD NORMATIVA DE LAS COMUNIDADES AUTONOMAS
}

\author{
POR \\ FEDERICO TORRES CURDI \\ Profesor de Derecho Administrativo
}

\begin{abstract}
SUMARIO: La POTESTAD NORMATIVA DF I AS COMUNIDAdes AUtÓnOMAS. La POSTESTAd LEGISLATIVA Y IA POTESTAD REGLAMENTARIA SU REGUL ACIÓN EN los ESTATUTOS DE AUTONOMIa Y EN LAS LEYES DE GOBIERNO Y ADMINISTRACIÓN: 1. La potestad legislativa.-2 La reserva de Ley: 2.1 Material; 2.2 Formal: La reserva de Ley hecha por una Ley estatal; 2.3 La cuestión en los Estatutos.-3. Atribución de potestades o de facultades: Examen del artículo 150.2 de la Constitución.-4. Ejercicio del control.-5. Otras normas con rango de Ley: 5.1 Decretos-leyes; 5.2 Decretos legislativos; 5.3 Normas en los Estatutos y Leyes de Gobierno y Administración.-6. Limites legislativos.-7. La potestad reglamentaria: 7.1 Organos que la tienen atribuida; 7.2 Denominación y jerarquía; 7.3 Reserva legal; 7.4 Control parlamentario: 7.4.1 Previo; 7.4.2 Posterior: 7.4.2.1 Organos estatutarios; 7.4.2.2 Organos jurisdiccionales. 7.5 Legitimación para recurrir: 7.5.1 Estado: 7.5.1.1 Por inconstitucionalidad; 7.5.1.2 Por ilegalidad. 7.5.2 Entes locales; 7.5.3 Particulares: 7.5.3.1 Directa: 7.5.3.1.1 Interés; 7.5.3.1.2 Competencia. 7.5.3.2 Indirecta. 7.6 ¿Cabe la suspensión?; 7.7 Nulidad total o parcial; 7.8 Publicación y entrada en vigor.-Notas.
\end{abstract}

\section{LA POTESTAD NORMATIVA DE LAS COMUNIDADES AUTONO- MAS.-LA POTESTAD LEGISLATIVA Y LA POTESTAD REGLA- MENTARIA.-SU REGULACION EN LOS ESTATUTOS DE AUTONO- MIA Y EN LAS LEYES DE GOBIERNO Y ADMINISTRACION}

\section{La potestad legislativa}

En nuestro ordenamiento jurídico las Comunidades Autónomas son también, junto al Estado, titulares de potestades legislativas y potestades reglamentarias; es decir, tienen el poder de dictar normas con rango de Ley y el poder de dictar Reglamentos; es decir, disposiciones con rango inferior a la Ley.

A pesar de que nuestra Constitución dedica todo un título a las Comunidades Autónomas, el título VIII, sin embargo, no alude de manera explícita a la potestad legislativa de las Comunidades Autónomas, sólo de forma indirecta alude a ella (1).

(1) Constitución, art. 152, 1. ${ }^{\circ}$ : «En los Estatutos aprobados por el procedimiento a que se refiere el artículo anterior, la organización institucional autonómica se basará en una Asamblea Legislativa elegida por sufragio universal con arreglo a un sistema de representación proporcional que asegure además la representación de las diversas zonas del territorio; un Consejo de Gobierno con funciones ejecutivas y administrativas, y un Presidente, elegido por la Asamblea, 


\section{Reserva de Ley.}

Las materias que deben regular las Comunidades Autónomas mediante Ley lo son siempre mediante la norma con tal nombre, sin que exista la diferencia de tipos de leyes, entre ley orgánica-ley ordinaria, como ocurre en el Estado.

La reserva de Ley, en las Comunidades Autónomas, la encontramos dependiendo de una doble fuente, que, a su vez, proviene, o al menos coincide, respectivamente, de la reserva material y reserva formal de Ley, y son:

\subsection{De La CONSTITUCión}

2.1.1 Se produce en el caso de leyes eventualmente dictadas por las Comunidades Autónomas para la aplicación directa de leyes orgánicas del Estado sobre derechos y deberes fundamentales.

2.1.2 Cuando la materia se refiere a los derechos $y$ deberes no fundamentales (2).

En este caso, la regulación provendría de Ley Ordinaria.

\subsection{LEY ORDINARIA}

La reserva (formal) de Ley a favor de la Asamblea Legislativa de una Comunidad hecha por una Ley Estatal, ¿es válida? Consideramos admisible dicha reserva siempre que se cumplan los siguientes requisitos:

a) Que la competencia sobre la materia esté asumida en el respectivo Estatuto.

b) Puede ser que vaya implícita en la propia Ley de reserva, y

c) Respeto al contenido competencial de la Constitución.

Creemos, sin embargo, que en las Comunidades Autónomas se deben regular por Ley tanto la Administración pública como la

\footnotetext{
de entre sus miembros y nombrado por el Rey, al que corresponde la dirección del Consejo de Gobierno. la suprema representación de la respectiva Comunidad y la ordinaria del Estado en aquélla. El Presidente y los miembros del Consejo de Gobierno serán políticamente responsables ante la Asamblea.»

Art. 153: «El control de la actividad de los órganos de las Comunidades Autónomas se ejercerá:

a) Por el Tribunal Constitucional, el relativo a la constitucionalidad de sus disposiciones normativas con fuerza de ley."
}

(2) Constitución. Título I, capitulo II, sección segunda, arts. 30 a 38, inclusive. 
Función pública de las respectivas Comunidades, y ello en base a (3).

De la misma forma, lo preceptuado por la Ley 30/1984, de 2 de agosto, de medidas para la reforma de la Función pública, artículo 1.․ 3: Se consideran bases del régimen estatutario de los funcionarios públicos, dictadas al amparo del artículo 149.18 de la Constitución, y, en consecuencia, aplicables al personal de todas las Administraciones públicas, los siguientes preceptos: Artículos $3 .^{\circ}$, 2 , e) y f) $; 6^{\circ}, 7 .^{\circ}, 8^{\circ}, 11,12,13.2 .3$ y $4 ; 14.4$ y $5 ; 16,17,18$, 19.1 y $3 ; 20,21.1$ a), b), c) d), e) y f), y $2 ; 22.1 ; 23,24,25,26$, 29, 31, 32, 33; Disposiciones adicionales tercera, 2 y 3 ; cuarta, duodécima y decimoquinta; Disposiciones transitorias segunda, octava y novena.

Pues en ambas Disposiciones hemos visto que se establece que por Ley se regulará tanto la Administración pública como la Función pública.

\subsection{LA CUESTIÓN EN los Estatutos}

Somos, pues, partidarios de la validez de esta reserva de Ley a favor de las Asambleas Legislativas de las Comunidades Autónomas.

Ambos casos de reserva de Ley los encontramos en el Estatuto de Autonomía de la Comunidad Valenciana, el primero referido al régimen electoral y estableciendo un quórum especial de tres quintos para la aprobación de la Ley (4).

En segundo lugar están las Leyes aprobadas por las Cortes valencianas, entre otras, de Ordenación de la Artesanía (5), Ley de Bases de Tasas (6), Ley del Instituto de la Pequeña y Mediana Industria (7).

$Y$ respecto a lo preceptuado por Ley que son básicas, o parte de sus preceptos se consideran básicos, tenemos la Ley de la Función pública valenciana, respetando los preceptos de la Ley

(3) Ley 12/1983, de 14 de octubre, del Proceso Autonómico. Administración pública, art. 12.3: «No obstante lo establecido en el apartado anterior, en los supuestos en que corresponda a las Comunidades Autónomas el desarrollo legislativo y la ejecución de la legislación básica del Estado en las referidas materias, se estará a lo dispuesto en la Constitución y en los respectivos Estatutos.n

Función pública, art. 27, 1: «La creación de Cuerpos o Escalas por las Comunidades Autónomas se hará mediante ley de sus respectivas Asambleas legislativas, dejando a salvo, en todo caso, las previsiones establecidas en el presente título." julio.

(4) Estatuto de Autonomia de la Comunidad Valenciana. Ley Orgánica 5/1982, de 1 de

(5) Ley de la Generalidad Valenciana 1/1984, de 18 de abril.

(6) Ley de la Generalidad Valenciana 6/1984, de 29 de junio.

(7) Ley de la Generalidad Valenciana 2/1984, de 10 de mayo. 
$30 / 1984$, en todos los preceptos que, según el artículo $1 .^{\circ}$, se consideran básicos para todas las Administraciones públicas (8).

Toda la demás legislación se realiza bien porque está considerada como exclusiva en el Estatuto, de desarrollo legislativo y ejecución en el marco de la legislación del Estado, o bien de ejecución de la legislación del Estado, o bien ejerciendo la potestad legislativa en materia de su propia competencia.

Por otra parte, las Comunidades Autónomas podrán asumir la atribución para dictar normas legislativas en el marco de los principios, bases y directrices fijados por una Ley estatal (9). Pero donde verdaderamente se nos plantea el problema es en el artículo 150.2 (10).

\section{Atribución de potestades o de facultades}

Dicho apartado nos dice: «El Estado podrá transferir o Delegar en las Comunidades Autónomas, mediante Ley Orgánica, facultades correspondientes a materia de titularidad estatal que por su propia naturaleza sean susceptibles de transferencia o delegación. La Ley preverá en cada caso la correspondiente transferencia de medios financieros, así como las formas de control que se reserve el Estado». Por lo que consideramos dudoso, en principio, que, a la vista de lo que nos dice la Constitución, las Comunidades Autónomas tengan atribuida «potestad legislativa», pues la Constitución emplea la palabra "facultades», y ello en base a lo siguiente:

Los autores que defienden la potestad legislativa, como Muñoz Machado (11), lo hacen atendiendo a una interpretación histórica,

(8) Ley de la Generalidad Valenciana. De la Función Pública 10/1985, de 31 de julio: «3. Se consideran bases del régimen estatutario de los funcionarios públicos, dictadas al amparo del artículo 149.1.18 de la Constitución, y, en consecuencia, aplicables al personal de todas las Administraciones públicas, los siguientes preceptos:

Articulos: $3^{\circ}, 2$, e) y f); $6^{\circ} ; 7^{\circ} ; 8^{\circ}: 11 ; 12 ; 13,2,3$ y $4 ; 14,4$ y $5 ; 16 ; 17 ; 18 ; 19,1$ y $3 ; 20 ; 21,1$, a), b), c), d), e) y f), y $2 ; 22,1 ; 23 ; 24 ; 25 ; 29 ; 31 ; 32 ; 33$; Disposiciones adicionales tercera, 2 y 3; cuarta, duodécima $y$ decimoquinta; Disposiciones transitorias segunda, octava y novena."

(9) Constitución, art. 150, 1: «Las Cortes Generales, en materias de competencia estatal, podrán atribuir a todas o a alguna de las Comunidades Autónomas la facultad de dictar, para sí mismas, normas legislativas en el marco de los principios, bases y directrices fijados por una ley estatal. Sin perjuicio de la competencia de los Tribunales, en cada ley marco se establecerá la modalidad del control de las Cortes Generales sobre estas normas legislativas de las Comunidades Autónomas."

(10) Constitución, art. 150.2: «El Estado podrá transferir o delegar en las Comunidades Autónomas, mediante Ley Orgánica, facultades correspondientes a materia de titularidad estata que por su propia naturaleza sean susceptibles de transferencia o delegación. La ley preverá, en cada caso, la correspondiente transferencia de medios financieros, así como las formas de control que se reserve el Estado."

(11) "Derecho público de las Comunidades Autónomas». Tomo I, p. 460. Tecnos, Madrid, 1982. 
con antecedentes en la Constitución española de 1931, o bien acudiendo a la doctrina alemana y forzando la interpretación del artículo 71 de la Ley Fundamental de Bonn, diciendo que el artículo 150.2 autoriza transferencias plenas, $y$ en el artículo 150.1, a transferencias parciales.

La exigencia de Ley Orgánica parece que está, además, en consonancia con esta interpretación.

Creemos, sin embargo, que la transferencia o delegación que la Constitución, en el precepto que estamos tratando, habilita a las Comunidades Autónomas es de ejecución administrativa, pero no legislativa, y nos basamos en defensa de nuestra posición en lo siguiente:

1. Los antecedentes parlamentarios, en los que se trata de permitir la prestación de servicios administrativos de carácter menor (12).

2. En la utilización de la palabra «facultad» por la Constitución, sin más adjetivos.

3. ${ }^{\circ}$ En la interpretación de las normas, ya que éstas se interpretarán según el sentido propio de sus palabras (13).

$4 .^{\circ} \quad$ La propia Constitución, en el artículo 153 (14), nos dice: «El control de la actividad de los órganos de las Comunidades

(12) Resumen de Actas del Congreso: «Es obvio que de lo que se trata es de permitir que la prestación de determinados servicios administrativos de carácter menor, englobados en competencias exclusivas estatales, sean hechos en colaboración con las Entidades autónomas...".

«En segundo lugar, para dejar claro que se trata de una mera técnica de descentralización administrativa...").

«En tercer lugar, se trata de introducir la cautela fundamental que no existía en el previo art. 144: la cautela de que sólo serán delegables o transferibles las funciones que por su propia naturaleza sean susceptibles de la utilización de dicha técnica...).

"Sin embargo, la incorporación al tiempo de ambas técnicas, la general y la especial, se entendería perfectamente si se considerara que los dos párrafos del articulo 150 se refieren a operaciones distintas: el primero a las delegaciones legislativas y el segundo a las transferencias y delegaciones de competencia puramente ejecutivas. La dificultad más seria con la que se enfrenta esta interpretación viene dada por la circunstancia de que el párrafo 2 exige que las delegaciones y transferencias puramente ejecutivas sean autorizadas por Ley Orgánica $y$, en cambio, el párrafo 1, para operaciones legislativas, se conforma con la habilitación mediante Ley Ordinaria. Dificultad que, sin embargo, no es insalvable si se comprende que la colaboración en el plano legislativo \{que es lo que propicia el párrafo 1) puede conferir menos poder efectivo que una transferencia de poderes ejecutivos, sobre todo cuando el Estado se desentiende definitivamente del ejercicio de la competencia.»

«Sin embargo, debe decirse que la cuestión discurre en la práctica y está siendo concretada en los textos legales de forma radicalmente distinta a la que acabamos de apuntar.)

AlzaGA, O.: En Constitución Española de 1978, Edic. del Foro, Madrid, 1978, pp. 473 y ss.

(13) Art. 3.1 C. C.: "Las normas se interpretarán según el sentido propio de sus palabras, en relación con el contexto, los antecedentes históricos y legislativos y la realidad social del tiempo en que han de ser aplicadas, atendiendo profundamente al espíritu y finalidad de aquéllas."

(14) Constitución, art. 153: «El control de la actividad de los órganos de las Comunidades Autónomas se ejercerá: 
Autónomas se ejercerá: b) Por el Gobierno, previo dictamen del Consejo de Estado, el del ejercicio de funciones delegadas a que se refiere el apartado 2 del artículo 150». Este artículo, y el apartado mencionado, viene a apoyar la tesis que sustentamos, tanto aisladamente como el artículo en su conjunto. El artículo regula el ejercicio del control de los órganos de las Comunidades, y según sea el órgano deviene la actividad, la naturaleza del acto que de él emana y, como consecuencia, el órgano que debe ejercer el control de dicha actividad, así el control se ejercerá:
a) Por el Tribunal Constitucional.
b) Por la Jurisdicción Contencioso-Administrativa.
c) Por el Tribunal de Cuentas.

Por lo que queda perfectamentre delimitado el control legislativo, los actos, reglamentos y actividad económica y presupuestaria.

\section{Ejercicio del control}

Nos queda el apartado b), que, repetimos, creemos a la transparencia y ejercicio de determinados servicios administrativos, porque si fuera transferencia legislativa, el control se ejercería por el apartado a), y nunca por el Gobierno, pues estaría controlando el poder legislativo y ejerciendo la potestad del Tribunal Constitucional.

El Gobierno ejerce el control sobre «el ejercicio de funciones delegadas» a "facultades correspondientes a materias de titularidad estatalı. Lo que tenemos en este precepto es un reforzamiento con carácter particular y concreto, de lo que con carácter general establece el artículo 155 de la Constitución, y dichos controles son el mantenimiento del nivel de eficacia de la Administración, y el respeto de los principios constitucionales de igualdad y solidaridad, como lo demuestra los incluidos en las dos Leyes Orgánicas 11 y $12 / 1982$, de 10 de agosto (15), de transferencias a las Comunidades de Canarias y Valenciana.

a) Por el Tribunal Constitucional, el relativo a la constitucionalidad de sus disposiciones normativas con fuerza de ley.

b) Por el Gobierno, previo dictamen del Consejo de Estado, el del ejercicio de funciones delegadas a que se refiere el apartado 2 del artículo 150

c) Por la jurisdicción contencioso-administrativa, el de la administración autónoma y sus normas reglamentarias

d) Por el Tribunal de Cuentas, el económico y presupuesto.»

(15) Incluimos la referente a la Comunidad Valenciana. Ley Orgánica 12/1982, de 10 de agosto: "2. Sin perjuicio de la competencia de los Tribunales, asi como de las especificas 
La realidad ha sido muy diferente. Los legisladores han interpretado extensivamente el precepto, muy discutible, $y$ en dicha interpretación se han apoyado las dos que hemos mencionado.

$Y$ en vez de ampliar las facultades de las Comunidades Autónomas, se ha convertido en una técnica para lograr la homogeneización competencial entre las Comunidades Autónomas constituidas por vía ordinaria y equiparadas a las creadas por vía especial (16). En idéntico sentido se pronuncia Boquera por lo que se refiere a la Comunidad Valenciana (16 bis).

\section{Otras normas con rango de Ley}

En el tema estudiamos las disposiciones del Gobierno con fuerza de Ley, concretamente los Decretos-leyes y Decretos legislativos, cuya cobertura constitucional es explícita como ya vimos (17). Lo que nos interesa ahora es saber si los Consejos de Gobierno de las Comunidades Autónomas pueden dictar actos con valor y eficacia de leyes formales, es decir, lo que conocemos con el nombre de Decretos-leyes y Decretos legislativos.

modalidades de control que sobre las facultades legislativas puedan establecer las leyes estatales a que se refiere el artículo 150 de la Constitución, la Comunidad Autónoma ajustará el ejercicio de las facultades transferidas a los siguientes principios y controles:

a) La Comunidad Autónoma está obligada a facilitar a la Administración del Estado la información que ésta solicite sobre la gestión del servicio.

b) Las facultades y servicios transferidos han de mantener, como mínimo, el nivel de eficacia que tenian antes de la transferencia; no podrán ser causa de desequilibrios financieros de la Comunidad o de destrucción grave de los recursos naturales y económicos, asi como tampoco podrán introducir desigualdad entre los individuos o grupos, ni ir contra la solidaridad individual o colectiva de los españoles.

c) En caso de incumplimiento de los requisitos anteriores, el Estado advertirá formalmente de ello a la Comunidad, y si ésta mantiene su actitud, el Gobierno podrá suspender a partir de los tres meses las facultades y servicios, dando cuenta de ello a las Cortes Generales, quienes resolverán sobre la procedencia de la decisión del Gobierno, levantando la suspensión o acordando la revocación de la facultad transferida.)

(16) Santamaria, J.: Apuntes de Derecho Administrativo, p. 466, ICADE, Madrid.

(16 bis) BOQUerA, J. B.: «El Estatuto de Autonomía de la Comunidad Valenciana, REVL, núm. 228, p. 657 .

(17) Constitución, art. 85: «Las disposiciones del Gobierno que contengan legislación delegada recibirán el título de Decretos legislativos".

Art. 86, 1: "En caso de extraordinaria y urgente necesidad, el Gobierno podrá dictar disposiciones legislativas provisionales que tomarán la forma de Decretos-leyes y que no podrán afectar al ordenamiento de las instituciones básicas del Estado, a los derechos, deberes y libertades de los ciudadanos regulados en el titulo I, al régimen de las Comunidades Autónomas ni at Derecho electoral generals). 


\subsection{DECRETOS-LEYES}

Debemos contemplar la posibilidad desde las dos únicas fuentes que pueden habilitar su admisibilidad en nuestro ordenamiento jurídico, la Constitución y los Estatutos de Autonomía.

\section{La Constitución}

No nos dice nada referente al ejercicio de tal potestad por parte de los Consejos de Gobierno de las Comunidades Autónomas. Tampoco prohíbe su ejercicio, lo que habilitaría su ejercicio si estuviera recogido en los respectivos Estatutos. En la doctrina encontramos partidarios de su admisión a Salas, y sosteniendo el valor excepcional de tal principio a Muñoz Machado. Creemos que es en los Estatutos de Autonomía donde debería haberse recogido, $y$ en ellos sólo lo encontramos en el Proyecto de Estatuto de Cataluña, donde entre las atribuciones del Consejo Ejecutivo figuraba la atribución de los Decretos-leyes. Sin embargo, no vino recogida en la redacción definitiva. Tampoco en ningún otro Estatuto encontramos referencia alguna a la posibilidad de ejercicio por parte de los Consejos de Gobierno de dictar Decretos-leyes.

\subsection{DeCretos LegisLativos}

Tampoco en los Decretos legislativos encontramos base constitucional explícita, igual que los Decretos-leyes tampoco los prohíbe. Aquí, en la delegación legislativa receptiva, nos encontramos con los Estatutos, que sí han recogido tal modalidad.

5.3 Normas en los Estatutos y LEYES de GobieRno y ADMINISTRACIÓN

Encontrándose regulada en los diferentes Estatutos y Leyes de Gobierno y Administración, en los preceptos siguientes:

Estatuto de Cataluña:

Ley Orgánica 4/1979, de 18 de diciembre. Artículo 33.1.

Ley 3/1982, de 25 de marzo. "Del Parlamento, del Presidente y del Consejo Ejecutivo de la Generalidad». Artículo 71, d).

Artículos 32 a 40, inclusive.

País Vasco:

Ley de Gobierno. Ley 7/1981, de 30 de junio, 
Galicia:

Estatuto de Autonomía. Ley Orgánica 1/1981, de 6 de abril. Artículo 10.

Ley de 22 de febrero de 1983, reguladora de la Junta y su Presidente. Artículo $4 .^{\circ}$

Andalucía:

Estatuto. Ley Orgánica 6/1981, de 30 de diciembre. Sólo contempla la delegación en Comisiones.

Aragón:

Estatuto de Autonomía. Ley Orgánica 8/1982, de 10 de agosto. Artículo 15.2: «La potestad legislativa de las Cortes de Aragón será únicamente delegable en la Diputación General, en los términos previstos en los artículos 82,83 y 84 de la Constitución.»

"Ley del Presidente de la Diputación General y de la Administración de la Comunidad Autónoma de Aragón». Ley de 22 de junio de 1984. Artículo 14: "Corresponde a la Diputación General:

a) Ejercer mediante Decretos legislativos la delegación legislativa en los términos previstos en el Estatuto de Autonomía y en la Ley $4 / 1983$, de 28 de septiembre, de las Cortes de Aragón.»

Asturias:

"Ley del Presidente del Consejo de Gobierno del Principado de Asturias». Ley de 5 de julio de 1984.

Baleares:

Estatuto de Autonomía. Islas Baleares. Ley Orgánica 2/1983, de 25 de febrero.

"Ley de Régimen Jurídico de la Administración de la Comunidad Autónoma de las Islas Baleares». Ley de 24 de octubre de 1984.

Canarias:

Ley $1 / 1983$, de 14 de abril. «Del Gobierno y de la Administración pública de la Comunidad Autónoma Canaria».

Cantabria:

Estatuto de Autonomía. Ley Orgánica 8/1981, de 30 de septiembre. Artículo 9.

Ley de 26 de abril de 1984. Del Régimen Jurídico del Gobierno y de la Administración de la Diputación Regional de Cantabria. 
Castilla-La Mancha:

Estatuto de Autonomía. Ley Orgánica 8/1982, de 10 de agosto. Artículo 9.2.

Castilla y León:

Estatuto de Autonomía. Ley Orgánica 4/1983, de 25 de febrero. Artículo 14.2 .

Extremadura:

Ley de 7 de julio de 1984. «Del Gobierno y de la Comunidad Autónoma de Extremadura». Artículo 25.

Madrid:

Estatuto de Autonomía. Ley Orgánica 3/1983, de 25 de febrero. Artículo 16.

Ley de 13 de diciembre de 1983. "Del Gobierno y Administración de la Comunidad de Madrid». Artículo 21.

Murcia:

Ley $1 / 1982$, de 18 de octubre. «De Gobierno y de la Administración pública de la Comunidad Autónoma de la Región de Murcia». Artículo 10.

Navarra:

Ley Orgánica 13/1982, de 10 de agosto. «De reintegración y amejoramiento del Régimen Foral de Navarra». Artículo 21.3.

Ley Foral 23/1983, de 11 de abril. «Reguladora del Gobierno y de la Administración de la Comunidad Foral de Navarra». Artículo 10 .

La Rioja:

Estatuto de Autonomía. Ley Orgánica 3/1983, de 9 de junio. Artículo 17.

Ley de 29 de diciembre de 1983. "Del Presidente y del Consejo de Gobierno de la Comunidad Autónoma de La Rioja». Artículo 22.

Valencia:

Ley $5 / 1983$, de 30 de diciembre. "De Gobierno valenciano».

Por lo que vemos que, exceptuando la Comunidad Autónoma de Andalucía, en el resto de las Comunidades Autónomas, bien en el Estatuto, bien en las leyes de Gobierno y Administración y en la Comunidad Foral de Navarra se encuentra expresamente regulada 
la delegación recepticia, con la particularidad que el ejercicio de tal potestad delegada está sometida a más restricciones en las Comunidades del País Vasco, Castilla y León, La Rioja y Valencia.

\section{Limites legislativos}

Además de los establecidos con carácter específico en cada Estatuto, referente a los distintos tipos de leyes, hemos de tener en cuenta los de carácter general que deben ser respetados por todas las Leyes de las Comunidades Autónomas, cuales son los principios de unidad, igualdad, solidaridad (18).

Hay también otros dos límites generales: uno, la territorialidad, y otro, y más importante que es la competencia, que, a su vez, tiene una manifestación interna en cuanto debe ser ejercida por la Comunidad y dentro de los límites de ésta, coincidiendo con la territorial, y otra externa a la propia Comunidad, que comporta la actuación del Estado, en cuanto éste no puede invadir la competencia de aquélla.

Aunque el principio de prevalencia se encuentra en el artículo 149.3 de la Constitución, solamente nos resta indicar que a esta supremacía de la Ley Estatal debemos añadir la de la Ley Comunitaria no sólo en cuanto a su aplicación directa, sino en lo que se refiere a la consideración como legislación básica, como ha ocurrido en el reciente Decreto legislativo 931/1986, de 2 de mayo, por el que se modifica la Ley de Contratos para adaptarla a las Directivas de la Comunidad Económica Europea (19). Como así ocurrirá en los sucesivos Decretos legislativos que el Gobierno dictará para adaptar nuestra legislación al acervo comunitario

(18) Constitución, art. 9: «1. Los ciudadanos y los poderes públicos están sujetos a la Constitución y al resto del ordenamiento jurídico

2. Corresponde a los poderes públicos promover las condiciones para que la libertad y la igualdad del individuo y de los grupos en que se integra sean reales y efectivas; remover los obstáculos que impidan o dificulten su plenitud y facilitar la participación de todos los ciudadanos en la vida politica, económica, cultural y social.

3. La Constitución garantiza el principio de legalidad, la jerarquia normativa, la publicidad de las normas, la irretroactividad de las disposiciones sancionadoras no favorables o restrictivas de derechos individuales, la seguridad juridica, la responsabildad $y$ la interdicción de la arbitrariedad de los poderes públicos."

(19) Real Decreto legislativo 931/1986, de 2 de mayo. Disposiciones finales. Primera: "Los articulos de la Ley de Contratos del Estado comprendidos en este Real Decreto legislativo tendrán. sin perjuicio del que corresponda a los demás artículos de la misma el carácter de legislación básica a los efectos del artículo 149, 1, decimoctavo, de la Constitución, y serán de aplicación a los contratos que celebren las Entidades gestoras y servicios comunes de la Seguridad Social, Comunidades Autónomas, Entidades locales y Organismos autónomos de unas y otras, siempre que dichos contratos estén comprendidos dentro del ámbito de los referidos articulos."

REVISTA DE ESTUDIOS.-8 


\section{La potestad reglamentaria. Su regulación en los Estatutos de Autonomia y en las Leyes de Gobierno y Administración}

El Reglamento, al igual que ocurre con la Administración del Estado, es la principal fuente, por su número, de las Comunidades Autónomas. Y esta importancia es motivo para que nos ocupemos de todas y cada una de las Comunidades, a través de los Estatutos de Autonomía y de las Leyes de Gobierno y Administración de cada una de ellas. Por ello, a continuación expondremos su proyección en las leyes mencionadas para examinar posteriormente su régimen jurídico.

\subsection{ORganos QUE LA TIENEN ATRIBUIDA}

En todas las Comunidades la tienen atribuida el Consejo de Gobierno, su Presidente y los Consejeros, bien expresamente en la mayoría o bien con carácter residual (20).

Manifestándose también en favor del reconocimiento a los Directores generales, aunque no expresamente en todas las Comunidades, asi como de otros órganos inferiores.

\subsection{DENOMINACIÓN Y JeRARQUía}

Todos los Estatutos y Leyes de Gobierno y Administración aluden a la denominación formal de potestad reglamentaria, aunque otros, además, son más explícitos, pues distinguen entre Reglamentos ejecutivos en competencia exclusiva, potestad reglamentaria en materias donde la competencia consista en desarrollo legislativo y ejecución de la legislación básica del Estado y la potestad reglamentaria cuando sólo tengan competencias de ejecución (21).

En todas, la denominación es de: 1) Decretos, cuando la dicta el Consejo; 2) del Presidente; 3) Ordenes de Comisiones Delegadas del Gobierno; 4) Ordenes de Consejerías; 5) Disposiciones de órganos inferiores por orden de su jerarquía.

Especificándose la jerarquía por el orden enunciado, y declarando la nulidad de las que infrinjan otras de jerarquía superior,

(20) Cataluña y Valencia.

(21) Estatuto de Andalucia, art. 41, cit. 
estableciendo en este caso una transposición de lo preceptuado en la Ley de Régimen Juridico (22).

Con la particularidad en Navarra de los Decretos y Ordenes forales, y en Canarias Ordenes interdepartamentales.

\subsection{Reserva DE LEY}

Al igual que en la potestad legislativa, sigue dependiendo de la Constitución, de los Estatutos de Autonomía y, además, de las Leyes de Gobierno y Administración y legislación emanada de la Comunidad, aunque respecto a estas dos últimas se suele abrir cauce a una deslegalización, bien para desarrollar y complementar la ley o bien como potestad residual.

Los problemas que exponemos en los epígrafes siguientes se plantean en todas las Comunidades Autónomas, pero me referiré a los de la Comunidad Valenciana, con indicación de alguna particularidad específica de otra que considere de interés.

\subsection{CÓNTROL PARLAMENTARIO}

Aunque normalmente, con este epígrafe, se alude al control jurisdiccional de la potestad, nosotros podemos distinguir, entre un control previo y otro posterior.

(22) Ley de Régimen Jurídico de la Administración del Estado, de 26 de julio de 1957, arts. 23 a 28 .

«Art. 23: 1. Ninguna disposición administrativa podrá vulnerar los preceptos de otro grado superior.

2. Las disposiciones administrativas de carácter general se ajustarán a la siguiente jerarquía normativa:

Primero, Decretos; segundo, Ordenes acordadas por las Comisiones Delegadas del Gobierno; tercero, Ordenes ministeriales; cuarto, disposiciones de autoridades y órganos inferiores, según el orden de su respectiva jerarquia."

"Art. 24. 1. Adoptarán la forma de Decreto las disposiciones generales no comprendidas en los artículos 10 y 12 de la Ley de Cortes y las resoluciones del Consejo de Ministros.

"Art. 25. 1. Las disposiciones y resoluciones de los Ministros adoptarán la forma de Ordenes e irán firmadas por el titular del Departamento.

2. Cuando la disposición o resolución administrativa dimane de una Comisión Delegada del Gobierno o afecte a varios departamentos, revestirá la forma de Orden del Ministro competente o de la Presidencia del Gobierno, dictada a propuesta de los Ministros interesados, constando, además, en el primer caso, en el libro de actas correspondiente.»

"Art. 26. La Administración no podrá dictar disposiciones contrarias a las leyes ni regular. salvo autorización expresa de una ley, aquellas materias que sean de la exclusiva competencia de las Cortes."

"Art. 27. Los Reglamentos, Circulares, Instrucciones y demás disposiciones administrativas de carácter general no podrán establecer penas ni imponer exacciones, tasas, cánones, derechos de propaganda y otras cargas similares, salvo aquellos casos en que expresamente lo autorice una ley votada en Cortes."

"Art. 28. Serán nulas de pleno derecho las disposiciones administrativas que infrinjan lo establecido en los artículos anteriores." 


\subsubsection{Control previo}

Nos viene establecido por la reserva material y formal de ley, y por los límites de la propia potestad, tanto de la materia como de la competencia sobre ella, dando lugar, a su vez, a respetar la jerarquía normativa, que anteriormente hemos mencionado.

\subsubsection{Control posterior}

También esta forma de control puede efectuarse por: Organos estatutarios y por Organos jurisdiccionales.

\subsubsection{Organos estatutarios}

Son los que en los Estatutos tienen como misión el control de actividad de los órganos, entre los que se encuentran el homónimo del Defensor del Pueblo, llámese Síndico de agravios, Justicia, etc., pues además de la protección y defensa de los derechos individuales, tienen la tutela del ordenamiento juridico, velando por su defensa y correcta aplicación.

\subsubsection{Organos jurisdiccionales}

El control se efectúa por la Jurisdicción Contencioso-Administrativa.

En todos los Estatutos se nos indica que los actos y acuerdos serán recurribles ante tal jurisdicción, con la particularidad de que si la potestad no es ejercida por el Concejo de Gobierno, previamente se ejercerá el recurso de alzada o de reposición hasta agotar la vía administrativa.

\subsection{LEGITIMACIÓN PARA RECURRIR}

La legislación estatutaria no suele entrar expresamente en este tema, ocupándose más de su propia legitimación activa que cuando forma parte de un procedimiento como demandada. A lo más se remite, unas veces a la Ley de Procedimiento Administrativo, y otras a la Ley de la Jurisdicción Contencioso-Administrativa. Por ello, y a la vista de nuestro ordenamiento, vamos a distinguir quiénes pueden recurrir los Reglamentos y actas de las Comunidades Autónomas, Estado, Entes locales y particulares, y, a su vez, entre impugnación directa e indirecta.

\subsubsection{Estado}

La Constitución dedica dos preceptos en virtud de los cuales se puede impugnar la actividad reglamentaria de las Comunidades 
Autónomas, pero a tenor de estos preceptos debemos distinguir si la motivación es por inconstitucionalidad o por ilegalidad.

\subsubsection{Motivos de inconstitucionalidad}

El artículo 161.2 de la Constitución (23) faculta al Gobierno a impugnar las disposiciones y resoluciones, es decir, los reglamentos $\mathrm{y}$ actos administrativos de las Comunidades Autónomas, emanadas de cualquiera de sus órganos. La particularidad de esta impugnación es que se debe basar en motivos de inconstitucionalidad.

\subsubsection{Motivos de ilegalidad}

Es el establecido en el artículo 153, c) (24), equiparándose, en este precepto, a cualquier otro ente público, y sometiéndose al control jurisdiccional de todos los actos y disposiciones de rango inferior a la Ley.

La diferencia fundamental está en la propia legitimidad activa, ya que el primero ha de ser ejercido por el Gobierno.

Particular interés presenta la Ley de 5 de octubre de 1981, que establece los criterios de legitimación en relación con las Comunidades Autónomas, considerando a todos los efectos como Administración, la de las Comunidades Autónomas y la de las Entidades sometidas a su tutela (25).

La norma citada trata en los dos artículos siguientes la legitimación para recurrir ante la jurisdicción contencioso-administrativa, de la Administración del Estado y la de la Comunidad Autónoma (26).

Por lo que se refiere a la Administración del Estado, ésta puede recurrir tanto las disposiciones de carácter general, como los actos emanados de la Administración de las Comunidades Autónomas, establecida en el artículo 3. ${ }^{\circ}$ (27). $Y$ aunque este punto no sea objeto de nuestro estudio, examinándolos comparativamente, planteamos las siguientes diferencias y cuestiones, reveladoras del diferente trato que la Ley otorga a ambas Administraciones:

(23) «2. El Gobierno podrá impugnar ante el Tribunal Constitucional las disposiciones $y$ resoluciones adoptadas por los órganos de las Comunidades Autónomas..)

(24) Cit.

(25) Ley 34/1981, 5 de octubre, art. 1: "A todos los efectos a que se refiere la vigente Ley reguladora de la Jurisdicción Contencioso-Administrativa (R. 1956, 1890 y N. Dicc. 18435) se entenderá como Administración pública la Administración de las Comunidades Autónomas. Las Entidades sometidas a la tutela de estas Comunidades tendrán igual consideración.».

(26) Ley cit., art. 2. : "La Administración del Estado estará legitimada para recurrir, ante la Jurisdicción Contencioso-Administrativa, las disposiciones generales y actos emanados de la Administración de las Comunidades Autónomas y entidades sujetas a la tutela de éstas."

(27) Ley cit., art. 3. : "Las Comunidades Autonómas podrán impugnar las disposiciones de carácter general que, dictadas por la Administración del Estado, afecten al ámbito de su autonomía." 
1. La Administración del Estado puede impugnar Reglamentos y actos de las Comunidades Autónomas.

2. La Administración del Estado puede impugnar Reglamentos y actos de las Entidades sometidas a tutela de las Comunidades Autónomas.

3. Las Comunidades Autónomas sólo podrán impugnar las disposiciones de carácter general de la Administración del Estado, si afectan al ámbito de su autonomía.

4. No podrán impugnar los Reglamentos ni actos de las Entidades sometidas a tutela del Estado.

5. ¿Hace falta justificar la legitimación? En esta cuestión es donde se aprecia el diferente trato otorgado a ambas Administraciones, pues así como en las Comunidades Autónomas, para poder impugnar es necesario que la disposición haya afectado al ámbito de su autonomía, en la Administración del Estado no dice nada, por lo que le está otorgando una habilitación de carácter general, sin que sea necesario la concurrencia de ningún otro requisito.

\subsubsection{Entes locales}

La Ley 7/1985, de 2 de abril, en el artículo 63.2 (28), habilita a los Entes locales para impugnar las disposiciones en actos de las Comunidades Autónomas. Este precepto, sin embargo, establece lo que pudiéramos llamar dos condicionantes: uno, que se refiere a Entidades locales territoriales, por lo que, además del Municipio, la Provincia y la isla, puedan impugnarlo las Entidades mencionadas en el apartado 2 del propio artículo (29). El otro nos viene establecido por el último párrafo de este propio apartado 2 «... que lesiona su autonomía, tal como ésta resulta garantizada por la Constitución y esta Ley». Por consiguiente, habremos de tener en

(28) Art. 63, 2: «Están igualmente legitimadas en todo caso las Entidades locales territoriales para la impugnación de las disposiciones y actos de las Administraciones del Estado y de las Comunidades Autónomas que lesionen su autonomía, tal como ésta resulta garantizada por la Constitución y esta Ley.»

(29) Art. 3, LBRL: "1. Son Entidades locales territoriales

a) El Municipio.

b) La Provincia.

c) La Isla en los archipiélagos balear y canario.

2. Gozan, asimismo, de la condición de Entidades locales:

a) Las Entidades de ámbito territorial inferior al municipio instituidas o reconocidas por las Comunidades Autónomas, conforme al artículo 45 de esta Ley.

b) Las Comarcas u otras Entidades que agrupen varios Municipios, instituidas por las Comunidades Autónomas de conformidad con esta Ley y los correspondientes Estatutos de Autonomia.

c) Las Areas metropolitanas.

d) Las Mancomunidades de Municipios." 
cuenta la regulación constitucional (30), cuya plasmación legal es el artículo 2.1 de la referida Ley reguladora de las Bases de Régimen Local (31).

Ahora bien, no son los principios teóricos, en los que debemos de fundamentar la impugnación, sino en expresiones positivas, y éstas se logran, en el caso que estamos tratando, bajo el principio de la competencia, es la competencia la que determinará o no la invasión o cercenamiento de la esfera de actividad de otra persona jurídica, $y$ es precisamente esto lo que preceptúa el mandato contenido en el apartado 2 del artículo 2, de la Ley que estamos copmentando (32).

\subsubsection{Particulares}

Veamos seguidamente las particularidades que comporta la. impugnación de los Reglamentos por parte de los particulares. Debemos distinguir entre la impugnación directa y la indirecta.

\subsubsection{Impugnación directa}

Respecto al problema que plantea el artículo 28,1, b) de la LJCA (33) referente a la posibilidad de impugnación directa, así como si se entiende derogado que el artículo 24 de la Constitución, nos remitimos al tema correspondiente.

La cuestión que en este caso se nos presenta es la siguiente:

¿Puede ser impugnado por las Entidades, Instituciones o Corporaciones de todo el territorio nacional, o sólo por los Entes del territorio de la Comunidad Autónoma?

(30) Art. 137: «El Estado se organiza territorialmente en municipios, en provincias y en las Comunidades Autónomas que se constituyan. Todas estas entidades gozan de autonomía para la gestión de sus respectivos intereses."

(31) Ley 7/1975, de 2 de abril, art. 2.

(32) Ley cit., art. 2: «1. Para la efectividad de la autonomía garantizada constitucionalmente a las Entidades locales, la legislación del Estado y de las Comunidades Autónomas reguladoras de los distintos sectores de acción pública, según la distribución constitucional de competencias, deberá asegurar a los Municipios, las Provincias y las Islas su derecho a intervenir en cuantos asuntos afecten directamente al círculo de sus intereses, atribuyéndoles las competencias que proceda en atención a las caracteristicas de la actividad pública de que se trate y a la capacidad de gestión de la Entidad local, de conformidad con los principios de descentralización y de máxima proximidad de la gestión administrativa a los ciudadanos.

2. Las Leyes básicas del Estado previstas constitucionalmente deberán determinar las competencias que ellas mismas atribuyan o que, en todo caso, deban corresponder a los Entes locales en la materia que regulen."

(33) LJCA, art. 28, 1, b): "Si el recurso tuviere por objeto la impugnación directa de disposiciones de carácter general de la Administración central, las Entidades, Corporaciones $e$ Instituciones de Derecho público y cuantas entidades ostentaren la representación o defensa de intereses de carácter general o corporativo, siempre que la disposición impugnada afectare directamente a los mismos, salvo en el supuesto previsto en el artículo 39, párrafo 3, en que bastará la legitimación a que se refiere el apartado a).» 
La respuesta la debemos enfocar desde el punto de vista del interés y de la competencia.

\subsection{Interés}

Las Entidades, Corporaciones o Instituciones, cuyo fin es la defensa de intereses individuales o corporativos de sus miembros, aunque no radiquen en el territorio de la respectiva Comunidad Autónoma, entendemos pueden impugnar los Reglamentos siempre que afecten a intereses personales o patrimoniales de sus miembros, y ello en base a:

1. El propio artículo 28,1, b) de la LJCA.

2. La cuasi-imposibilidad del particular de llevarla a cabo.

3. El principio propugnado por el artículo 24 de la Constitución.

Posición ésta, que se refuerza en el caso de que el particular no tuviese su domicilio, ni intereses patrimoniales en la Comunidad Autónoma.

\subsection{Competencia}

La debemos comtemplar para el caso que estamos tratando, desde un punto de vista negativo, en el sentido, tanto en la competencia territorial como por razón de la materia, y por consiguiente, ni puede ejercer competencias que no tiene, y en caso de tenerlas, prorrogarlas más allá de sus límites territoriales causando efectos personales a reales.

\subsubsection{Impugnación indirecta}

Aparte la habilitación contenida con carácter general en el artículo 39, 3, de la LJCA que posibilita impugnar directamente (34), los particulares pueden impugnar los actos administrativos, basada en un Reglamento ilegal, a partir de la notificación de aquél.

Los Estatutos se ocupan de los diferentes recursos, reposición, alzada e incluso revisión (35), hasta agotar la vía administrativa, y dejar expedita la vía jurisdiccional.

(34) LJCA, cit., art. 39, 3: «No obstante, serán asimismo impugnables, en todo caso, las disposiciones de carácter general que hubieren de ser cumplidas por los administrados directamente, sin necesidad de un previo acto de requerimiento o sujeción individual."

(35) Estatuto de Andalucia, Ley 6/1984, de 21 de julio, art. 49: "1. Los actos dictados por los órganos que no agoten la via administrativa son susceptibles de recurso de alzada.

2. Contra los actos dictados por los órganos de gobierno de los Organismos Autónomos. procederá el recurso de alzada ante el titular de la Consejeria a que se encuentre adscrito.

3. El recurso extraordinario de revisión se interpondrá ante el Consejero competente en razón de la materia.) 


\subsection{CABE LA SUSPENSIÓN}

Siendo propia del tema correspondiente a los Reglamentos en general, el estudio de la suspensión, a petición de los particulares, cuando se refiere a impugnación indirecta, nos corresponde en esta lección el estudio de la suspensión específica de las disposiciones reglamentarias de las Comunidades Autónomas.

Anteriormente, nos hemos referido a la impugnación que habilita el artículo 161,2 , de la Constitución. Pues bien, el último párrafo de dicho apartado, indica que la impugnación producirá la suspensión (36), referida tanto a Reglamentos como a actos administrativos, con la particularidad de que se establece un plazo que expira a los cinco meses para que el Tribunal la ratifique o levante.

\subsection{NULIDAD TOTAL O PARCIAL}

Esta potencial declaración del Tribunal está en relación a la impugnación directa o indirecta. Es decir, los efectos de la sentencia son muy diferentes, pues cuando se estima un recurso interpuesto directamente, produce la anulación del reglamento, $y$ cuando se ha interpuesto indirectamente, su efecto es la anulación del acto, quedando válidos los demás actos promovidos a su amparo.

\subsection{PUBLICACIÓN ENTRADA EN VIGOR}

En todos los Estatutos hemos encontrado preceptos en los que se preceptúa la publicación de las disposiciones de carácter general en el respectivo "Boletín Oficial» de la Comunidad (37), siendo el plazo de su entrada en vigor, desde la publicación o en el plazo de veinte días.

Para terminar, diremos que, en general, se aprecia, por una parte, un gran mimetismo respecto al ejercicio de la potestad reglamentaria de la Administración central, y por otra, apreciamos un excesivo ejercicio de dicha potestad por parte de órganos inferiores que nos hace dudar, a veces, de la habilitación que la sustenta.

El paralelismo mencionado se distorsiona otras veces, no en el fondo, sino en la forma, como es el caso de la declaración de

(36) Constitución, art. 121, 2: "La impugnación producirá la suspensión de la disposición o resolución recurrida, pero el Tribunal, en su caso, deberá ratificarla o levantarla en un plazo no superior a cinco meses."

(37) Comunidad Valenciana, Ley cit., art. 49. Comunidad de Madrid, Ley cit., art. 51,3 Comunidad de Andalucia, Ley cit., art. 46. 
urgencia para ocupación de los bienes afectados por expropiación, y que el artículo 52 de la LEF indica. Pues bien, en vez de ser mediante acuerdo de un órgano colegiado, como mayor garantía de los derechos individuales, reconocidos en la Constitución, y así es en la Ley; se efectúa dicha declaración por una simple resolución administrativa, no acorde, a nuestro entender, con la jerarquía del órgano que la emite.

8. Los preceptos reglamentarios en los Estatutos y en las Leyes de Gobierno y Administración

País Vasco:

Ley Orgánica 3/1979, de 18 de diciembre. Artículos 20.4 y 38.3 .

Ley $7 / 1981$, de 30 de junio. Artículo $\left.8 .^{\circ}, c\right)$.

Cataluña:

Ley Orgánica 4/1979, de 18 de diciembre. Artículos 25.2 y 40.2 .

Ley $3 / 1982$, de 23 de marzo.

Galicia:

Ley Orgánica 1/1981, de 6 de abril. Art. 37.2.

Ley de 22 de febrero de 1983.

Andalucia:

Ley Orgánica 6/1981, de 30 de diciembre.

Ley $3 / 1983$, de 21 de julio.

Aragón:

Ley Orgánica 3/1982, de 10 de agosto.

Ley de 22 de junio de 1984.

Asturias:

Ley Orgánica 7/1981, de 30 de diciembre.

Ley de 5 de julio de 1984.

Baleares:

Ley Orgánica 2/1984, de 25 de febrero.

Ley de 24 de octubre de 1984.

Canarias:

Ley Orgánica 10/1982, de 10 de agosto.

Ley de 14 de abril de 1983. 
Cantabria:

Ley Orgánica 8/1981, de 30 de diciembre.

Ley de 26 de abril de 1984.

Castilla-La Mancha:

Ley Orgánica 9/1982, de 10 de agosto.

Ley de 25 de abril de 1984.

Castilla y León:

Ley Orgánica 4/1983, de 25 de febrero.

Extremadura:

Ley Orgánica 1/1983, de 25 de febrero.

Ley de 7 de junio de 1984.

Madrid:

Ley Orgánica 3/1983, de 25 de febrero.

Ley de 13 de diciembre de 1983.

Murcia:

Ley Orgánica 4/1982, de 9 de junio.

Ley de 18 de octubre de 1982.

Navarra:

Ley Orgánica 13/1982, de 10 de agosto.

Ley de 11 de abril de 1983.

La Rioja:

Ley Orgánica 3/1982, de 9 de junio.

Ley de 29 de diciembre de 1983.

Comunidad Autónoma Valenciana:

Ley Orgánica 5/1982, de 1 de julio.

Ley $5 / 1983$, de 30 de diciembre. 
REALA-1989, núm. 242. TORRES CURDI, FEDERICO. SOBRE LA POTESTAD NORMATIVA DE LAS...

REALA-1989, núm. 242. TORRES CURDI, FEDERICO. SOBRE LA POTESTAD NORMATIVA DE LAS... 
REALA-1989, núm. 242. TORRES CURDI, FEDERICO. SOBRE LA POTESTAD NORMATIVA DE LAS...

REALA-1989, núm. 242. TORRES CURDI, FEDERICO. SOBRE LA POTESTAD NORMATIVA DE LAS... 